\title{
Informes de trabajo: Proyecto Guatin
}

George Serracino, Rubén Stehberg, Gloria Liberman

\section{Proyecto Guatin}

Los problemas arqueológicos en la zona de San Pedro de Atacama son múltiples y variados. En general, se han hecho recolecciones superficiales de yacimientos precerámicos y excepcionalmente pequeñas excavaciones que no han sido publicadas. También se ha estudiado en su gran mayoría los cementerios de la zona descubiertos por Le Paige. En consecuencia, sentimos la necesidad de estudiar en forma sistemática un hábitat, para completar el desarrollo integral de la zona.

De acuerdo a la recomendación de Le Paige comenzamos con el yacimiento Guatin por los siguientes motivos:

En la superficie de este lugar existe todo tipo de material arqueológico, desde el "proyectil point", de Ghatchi, hasta cerámica reciente. Por lo tanto, pensamos que un estudio del lugar arrojará una visión completa del desarrollo ocupacional humano en la zona de San Pedro de Atacama.

También el lugar se presta para hacer un estudio paleoecológico de la zona. La posición geográfica de Guatin es un foco central en el cual confluyen una serie de yacimientos arqueológicos ubicados a su alrededor. En el NO se ubican los yacimientos de Pelún y otros a lo largo de la Quebrada de Puritama, al NE se encuentra la Quebrada de Puripica con varios yacimientos en ambos lados, especialmente el yacimiento de $\mathrm{Pu}$ ripica y Morteritos, al SO el yacimiento de Loma Negra y Ghatchi y al SE yacimientos en los dos costados de la quebrada de Chaxas.

Consideremos que el estudio debe tener varias etapas debiendo abarcarse el área en todos sus aspectos, desde hoy día hasta los tiempos más remotos. Por lo tanto, trazamos un programa de trabajo con las siguientes etapas:

1. Estudio del material recogido en la superficie de Guatin por el P. Le Paige que hoy día se encuentra en el Museo de San Pedro de Atacama.
2. Estudio geomorfológico.

3. Estudio antropológico de un pastor de los Andes que es uno de los pocos pastores que todavía vive solo y es el único habitante actual del área.

4. Estudios etnofaunístico y etnobotánico de la zona.

5. Mapeo topográfico y estructural del área.

6. Recolecciones superficiales en forma de muestreo.

7. Excavaciones arqueológicas en puntos clave con las posibilidades de ubicar el material en posiciones estratigráficas para sacar muestras de $\mathrm{C} 14$.

Con respecto a este proyecto se han efectuado hasta hoy día cuatro expediciones: mayo 1972, agosto 1972 , febrero 1973 y julio 1973. Participaron en dichas expediciones las siguientes personas: George Serracino, como director; Rubén Stehberg, químico y alumno de arqueología; Gloria Liberman, historia y geografía; Eduardo Feuerhage, arquitecto, y Juan Salva y Plácido Cruz, auxiliares del Museo.

Hasta la fecha el proyecto está en una fase muy avanzada y se efectuaron o están en proceso de análisis de laboratorio las siguientes etapas:

1. Estudio y seriación del material lítico de la superficie de Guatin que se encuentra en el Museo.

2. Estudio geomorfológico. Se hizo un pozo de $2 \mathrm{~m}$ de profundidad del cual se sacaron muestras de tierra cada $5 \mathrm{~cm}$ para el análisis de $\mathrm{pH}$, de granulometría y morfoscópico. El trabajo de laboratorio para los primeros dos análisis está terminado. El tercer análisis está todavía en proceso de laboratorio.

3. El informe etnobotánico está en prensa en la revista Antropología del Depto. de Ciencias Antropológicas y Arqueología, Universidad de Chile (Santiago), próxima a aparecer.

4. Se realizó un estudio antropológico sobre la vida de Juan Vilca, el único habitante de Guatin. Los datos recogidos en el terreno 
están en proceso de redacción para su eventual publicación.

5. Se terminó el levantamiento topográfico estructural del área y su estudio será presentado al VII Congreso Chileno de Arqueología, a realizarse en Punta Arenas.

6. Se comenzó a estudiar un sector del área denominado $\mathrm{W} 3$ que presenta el mayor número de complejos estructurales.

7. En este sector se estudiaron las diversas estructuras y sus características arquitectónicas.

8. Se hizo una recolección superficial de la cerámica dentro de las estructuras del sector W3 y se terminó su respectiva seriación.

9. Se excavó una cuadrícula en el recinto 7 del sector W3. Se terminó el estudio de la cerámica y lítico recogido en la excavación.

A continuación damos brevemente los resultados alcanzados hasta el momento, sin conclusiones absolutas. Para cada parte se entregará un informe completo una vez terminada la etapa en terreno y sus relativos análisis en el laboratorio.

1. Del pozo geomorfológico se desprende que en el área hubo dos períodos de lluvias torrenciales intercaladas por períodos de sequía en tiempo reciente. Por ahora no pueden relacionarse estas etapas con períodos culturales debido a que el pozo mismo no ha arrojado estratos culturales.

2. Según las evidencias de cerámica el sector W3 fue ocupado durante los siguientes períodos: reciente, Colonial, Tardío (cerámica negra engobada y San Pedro III) y Medio (cerámica negra pulida).
3. Todas las estructuras están contruidas con rodados de río no acanterados, sin argamasa. Actualmente en toda la zona se usa argamasa y acanteran las piedras (ejemplo, casa actual de Juan Vilca) y otras casas de pastores en Guatín son de doble agua que también usan argamasa o piedras acanteradas; esto nos inclina a pensar que las estructuras del sector W3 pertenecen a una época tardía y colonial temprana. Las piedras han sido reutilizadas en construcciones posteriores. Evidencias de esto se verifican encontrando morteros cónicos en las paredes de los recintos y cúmulos de piedras fuera de los recintos.

4. No ha sido posible determinar el patrón de poblamiento en las diferentes épocas señaladas. Sin embargo, nos atrevemos a decir que el conjunto estructural según su morfología puede dividirse en tres partes: 1) Sector de campos de cultivo rectangulares formando varios paralelogramos conjuntos; 2) sector de campos de cultivos ovales en su totalidad formando una figura irregular asistemática, y 3) sector de pircas, unas posiblemente habitacionales y una pirca que por su gran dimensión y aislamiento de los demás conjuntos podría haber servido de corral.

5. El complejo estructural del número 1 tiene cerámica negra pulida en la superficie, además de la cerámica tardía y colonial, mientras que el sector 2 carece de cerámica negra pulida. De esto se desprende que el sector de campos de cultivos y sus recintos habitacionales fueron utilizados en el Período Tardío y Colonial, mientras que el sector de campos ovales fue usado desde un período más temprano de la cerámica negra pulida. 